\title{
Parental Perceptions of Grit: First Steps Towards Building Effective Character Education Programs
}

\author{
Cara Song and Nancy Maynes
}

Received: Jan. 25, 2019

Accepted: April 29, 2019

Published: May 1, 2019

doi:10.5296/jse.v9i2.14577

URL: https://doi.org/10.5296/jse.v9i2.14577

\begin{abstract}
In 2007, Angela Duckworth and her team of researchers coined the term "grit" to define a non-cognitive construct that entails perseverance and passion for long-term goals. In this exploratory study, descriptive survey methodology was used to determine what parents and their preadolescent students of a Northern Ontario public school $(N=8)$ knew and perceived about grit. Regardless of prior knowledge, participants shared perceptions of how they believed schooling should be and specific strategies perceived to support grit development. In addition, using variations of the 8-Item Grit Scale (the Grit-S), it was found that children considered themselves to be grittier than their parents perceived them to be. Collectively, these findings suggest the need for further study on perception research, on the assessment of non-cognitive traits, and on grit itself. Most importantly, these findings imply the premature incorporation of grit into school board character education policies based on inconsistent grit knowledge and interpretation.
\end{abstract}

Keywords: grit, resilience, character education, parental involvement 


\section{Introduction}

Aristotle and Confucius both reflected upon questions such as these: "What kind of person do we want our children to be and how can we raise and educate them to be that way?" (Althof \& Berkowitz, 2008, p. 496). Aristotle "described the best people and the acts they found admirable, and from his descriptive work, [predicted that] the focus will remain on the formation of habits and eudaimonia,"-happiness or well-being (Noddings, 2012, p. 166). For philosopher John Dewey, the purpose of education was to "foster actions, habits, and a sense of moral self-worth characterized by a growing willingness to choose the common good over the good of the self more narrowly conceived" (Bergman, 2005, p. 52). These notions focus on morality and brought to light the importance of what is now known as character education-in simplest terms, "curriculum developed to teach children about the essential traits needed to build good character" (Almerico, 2014, p. 2). While study of morality is at the core of character education (Almerico, 2014; Althof \& Berkowitz, 2008; Narvaez \& Lapsley, 2008), researchers and thinkers have turned to developmental approaches (such as those of Jean Piaget and Lawrence Kohlberg) and, more recently, psychology (like the approaches of Carol Dweck, Angela Duckworth, and Paul Tough) to support the necessity of character education in schools today.

Traditional character education approaches "assert there are universal values that must be explicitly taught to students" (Winton, 2010, p. 221). To economists and researchers, these are non-cognitive skills; to psychologists, these are personality traits; to most others, these are known as character (Tough, 2012, pp. xiv-xv). Persistence, self-control, optimism, curiosity, conscientiousness - these, among others, are what have been universally agreed upon as the traits that are necessary for a child to develop in order to succeed academically, emotionally, and mentally (Duckworth, Quinn, \& Seligman, 2009; Egalite, Mills, \& Greene, 2016; Tough, 2012).

In 2007, after researching teaching strategies to foster self-control in children, Angela Duckworth and her team identified a trait that encompasses perseverance, passion, and self-control: grit (Duckworth, Peterson, Matthews, \& Kelly, 2007). This builds upon Carol Dweck's (2006) concept of the growth mindset - the belief that "your basic qualities are things you can cultivate through your efforts" (p. 8). Both of these concepts shifted the framework for character education, with many educators becoming aware of the importance of these constructs. For example, in 2008, the Ontario Ministry of Education released a revised version of Finding Common Ground: Character Development in Ontario Schools, K-12, a character development initiative that aimed to embed character education within the existing academic curriculum. While the focus of the initiative stated that, "there are universal attributes that schools and communities value" (Ontario Ministry of Education, 2008b, p. 2), professional development began to focus on fostering student voice and motivation through teacher-student relationships, inquiry-based instruction, and effective assessment processes, consistently citing Duckworth's construct of grit and Dweck's growth mindset as references (Ontario Ministry of Education, 2013, 2016a). This is, in fact, reminiscent of what is being seen across North American education, as "grit [revives] a long-standing conversation about character education in schools" (Stokas, 2015, p. 514). 
However, despite initial research conducted by Duckworth et al. (2007), the pedagogical specifics about fostering grit remain unclear, other than the acknowledgement that it is "a disposition held by highly successful individuals" (Stokas, 2015, p. 513) and that "it is essential to also develop a school culture that emphasizes character and grit" (Dean, 2014; as cited in Bashant, 2014, p. 16). A main pedagogical challenge lies in inconsistent measurement practices, such as self-report surveys and scales, which are used to assess attributes other than cognitive ability (Duckworth \& Yeager, 2015, p. 238). Additionally, by relating grit to other non-cognitive traits like resilience and perseverance, much can be hypothesized about the effect of parent and guardian perceptions on the fostering of grit, but little has been proven. Supportive relationships and positive parental influence are among protective factors that "can help to mitigate the harmful effects of risk" (Schon \& Bartlet, 2008; as cited in Jackson, Whitehead, \& Wigford, 2010, p. 70) in order to develop grit; and "the views children have of their own learning possibilities are influenced by their parents' perceptions of their competencies" (Karkkainen, Raty, \& Kasanen, 2009, p. 407). By understanding what parents know about grit, a foundation is set towards building an effective character education program that has some potential to truly foster grit.

\section{Defining Grit}

Although Duckworth's recent work on grit has "given shape to the investigation of grit in the field of American education" (Stokas, 2015, p. 513), grit is not an unfamiliar concept to non-educators. In fact, "American culture readily connects the cowboy to grit" (Stokas, 2015, p. 517). Stokas outlined the traits that popular culture has attributed to a gritty cowboy: courage, endurance through physical suffering, an uncomplaining personality, and the disposition of a boxer-physically and mentally disciplined (Stokas, 2015). Arias (2016) also pointed out that "fictional literature is laden with many stories of heroic protagonists that [who] are successful in emotionally connecting and appealing to people of all ages," and that these protagonists possess "emotional capacities of showing resiliency and possessing high self-efficacy" (p. 12). This perhaps unintentionally signals to viewers the importance of non-cognitive traits such as grit.

However, Duckworth et al. (2007) formally defined the construct of grit after finding that "grittier individuals had attained higher levels of education than less gritty individuals of the same age" (p. 1098). They described the construct as follows:

We define grit as perseverance for long-term goals. Grit entails working strenuously toward challenges, maintaining effort and interest over years despite failure, adversity, and plateaus in progress. The gritty individual approaches achievement as a marathon; his or her advantage is stamina. Whereas disappointment or boredom signals to others that it is time to change trajectory and cut losses, the gritty individual stays the course. (pp. 1087-1088)

In a series of six studies, Duckworth et al. (2007) used a self-report grit scale and found that grit, above other non-cognitive constructs, could predict achievement more accurately than IQ. This included research among secondary and post-secondary students, United States Military Academy cadets, and Scripps National Spelling Bee competitors. While the grit that Duckworth et al. (2007) described encompasses many of the traits that Stokas (2015) attributes 
to the cultural cowboy, the educational construct of grit focuses on progress rather than the consistent endurance of challenges we see in Western genre representations.

Grit also shares similarities to other non-cognitive constructs, such as self-control, persistence, conscientiousness, and resilience, but rather than individually defining each construct, grit holds roots in each to encompass them. Grit involves deliberate practice and making choices that require "[sacrificing] short-term pleasure for long-term gain" (Duckworth \& Seligman, 2005, p. 944); understanding "that it is ok to feel confused when learning something new" (Bashant, 2014, p. 14); thus, practising self-reflection (Cross, 2014, p. 5) and continuing forward in the face of adversity (Duckworth et al., 2007, p. 1088). A key characteristic of grit is "its emphasis on long-term stamina rather than short-term intensity" (Duckworth et al., 2007, p. 1089), which ties specifically to self-control, "the voluntary regulation of conflicting thoughts, feelings, and actions in accordance with long-term goals" (Duckworth, White, Matteucci, Shearer, \& Gross, 2016, p. 329). In defining grit, Duckworth and Seligman (2005) directly address arguments surrounding academic underachievement: "We believe that many of America's children have trouble making choices that require them to sacrifice short-term pleasure for long-term gain, and that programs that build self-discipline may be the royal road to building academic achievement" (p. 944). However, little is known about specific pedagogies involved in fostering grit aside from our efforts to model grit to children, and to encourage growth mindsets as children develop.

\section{Modelling}

As it is a relatively new concept, research findings on effective teaching practices relating to grit are limited, however, Duckworth et al. (2009) have noted: "mean level increases in grit across the lifespan suggest that it may be improved by intervention" (p. 546). In the same study, Duckworth et al. (2009) linked student learning and grit levels with teachers' grit levels: teachers who are better able to communicate, better able to adapt their teaching strategies to student learning, who had high energy levels and positive attitudes, and were able to persevere when teaching challenges arose, not only served as models for students, but they were also more effective in improving student outcomes. This modelling approach requires that educational leaders and educators be well versed about grit and growth mindset (Fitzgerald \& Laurian-Fitzgerald, 2016, p. 65).

\section{Growth Mindset}

Dweck's concept of the growth mindset "is possibly one of the strongest contributors to the development of grit" (Laursen, 2015, p. 23). Duckworth et al. (2007) linked grit to growth mindset further by describing grit as a deliberate focus on long-term goals, rather than "as a drive to complete manageable goals that allow for immediate feedback on performance" ( $\mathrm{p}$. 1089). Similarly, Dweck and Leggett (1988) identified two theories of intelligence: entity and incremental. Yaeger and Dweck (2012) stated: "The entity theory world is about measuring your ability and everything (challenging tasks, effort, setbacks) measures your ability;" while "the incremental world is about learning and growth, and everything (challenges, effort, setbacks) is seen as being helpful to learn and grow" (p. 304). Focusing on developing a mindset that aligns with an incremental theory of intelligence allows for the development of a 
growth mindset, similar to how focusing on progress towards a long-term goal takes precedence over short-term achievement in fostering grit. According to Duckworth, "kids may have the wrong beliefs and have misunderstandings about skill development...beliefs that stand in the way of tapping into performance traits" (as cited in Bashant, 2014, p. 14). By acknowledging and praising students "for the effort they put into learning" rather than for ability - a key practice in fostering a growth mindset - educators can contribute to students' grit (Laursen, 2015, p. 23).

\section{The Research Problem}

Although Angela Duckworth introduced the educational construct of grit in 2007 (see Duckworth, Peterson, Matthews, \& Kelly, 2007), she revived buzz among the general public around the already popular notion of growth mindset and shifted attention to grit when she spoke at a Technology, Entertainment, and Design (TED) Conference in April 2013, in New York City, New York. In studying self-control and self-discipline (Duckworth \& Seligman, 2005, 2006), she and her team identified students who were more likely to graduate, win competitions, and persevere through challenges as having higher levels of grit- "perseverance for long-term goals" (Duckworth et al., 2007, p. 1087).

The evidence supporting the need for grit points to the necessity of teaching it in elementary schools. In particular, researchers present grit as a potential approach in increasing student success in and outside of school (Duckworth et al., 2007), as high levels of the construct point to achievement in all domains: academic, vocational, and avocational (Von Culin, Tsukayama, \& Duckworth, 2014, p. 306). Developing grit would then theoretically, hand-in-hand with academic achievement, improve adolescent mental health. However, the question of how grit is taught remains relatively unknown.

Despite this gap in current knowledge, provincial educational frameworks adopted grit and related terminology into their documents. For instance, the Ontario Ministry of Education released the first phase of $21^{\text {st }}$ Century Competencies, a document to support Ontario school boards and branches in providing professional development to "foster deeper learning and global competencies in students," and to "implement innovations in learning and teaching" (Ontario Ministry of Education, 2018), citing both grit and a growth mindset as competencies that would benefit students (Ministry of Education, 2016). The teaching of grit has also been featured in national and international media beyond those that cater specifically to educators, such as the Huffington Post, Forbes, and the Globe and Mail (see Hutton, 2017; Perlis, 2013; Wente, 2016). Placing importance on fostering grit in schools without concrete pedagogical approaches has left educators lacking confidence in "their abilities as character educators" (Waters \& Russell, 2017, p. 53). To ensure the effectiveness of character education programming that focuses on grit, researchers first need to address the existing gaps in knowledge, including what is known and perceived about grit from all school stakeholders.

\section{Research Questions}

The purpose of this study was to explore parents' and guardians' perceptions of grit in their preadolescent children in relation to grit in the general population of a Northern Ontario school 
district. Secondarily, a correlation between parents' and guardians' perceptions of grit in their children and the grit levels found in these children through a grit level self-assessment tool was examined.

The research questions of this study are as follows:

- What do parents know about grit?

- How do parents perceive their children in relation to grit?

- How do parents perceive the school community in relation to grit?

- How do these perceptions correlate with self-reported development of grit in children?

The ultimate goal of this study was to provide researchers and educational planners with an indication of what parent perceptions are surrounding grit, to identify how parent perceptions matter in grit development, and to provide direction in character education program planning.

\section{Theoretical Framework}

In her TED Talk, Duckworth (2013) cited the use of a growth mindset as a starting point (4:51), however specific pedagogies in fostering grit continue to be debated as a result of two main gaps in current literature: measurement and assessment of grit, and how grit is perceived among those in the school community. First, a lack of reliable measurement procedures prevents true consistency in assessing grit, among other non-cognitive skills. Currently, the main form of collecting data relating to non-cognitive skills is self-report measures, which offer several limitations and considerations, including bias. Whether or not this is the most accurate form of measurement and assessment remains highly debated in the psychological field (Duckworth \& Yaeger, 2015, p. 240). Since character assessments in schools are often based on self-report or anecdotal notes of observations (Duckworth \& Yaeger, 2015), it is uncertain as to whether programming is effective or not.

A second discrepancy in current grit literature shows a lack of understanding in the knowledge and perceptions of school stakeholders, including parents, guardians, and other parties who directly affect student development through their influence as protectors. In fact, the significant link between parental and guardian perceptions and child self-efficacy is well researched. How parents view their children does, in fact, affect the psychological development of their children; this has been proven both in psychological realms (Baldry \& Farrington, 2005; Eisman, Stoddard, Heinze, Caldwell, \& Zimmerman, 2015) and in educational realms (Bashant, 2014; Karkkainen, Raty, \& Kasanen, 2009). In researching perceptions of resilience in preadolescent students, Karkkainen et al. (2009) found that how parents understood resilience, and how they perceived their child in relation to resilience made an impact on how resilient their children were. Because of this, parents and guardians are not discounted in educational planning - in particular, previous Ontario Ministry of Education initiatives noted the importance of involving family members through a whole-school effort, with parents and families carrying primary responsibility for their child's development (Ontario Ministry of Education, 2008, p. 4). 
With this in mind, and in considering the landscape of grit research and of Ontario education, a realistic goal in program planning is to consider stakeholder perceptions in a cooperative approach, in order to begin the development of assessment measures to determine best practices.

\section{Methodology}

A descriptive survey research approach was used for this study, as the research sought to explain what the parental understanding of grit is, and if there is an existing relationship between their perceptions and their child's grit level. The research is exploratory, rather than inferential-defining the work as descriptive research (Knupfer \& McLellan, 2001, p. 1196).

A questionnaire with both closed- and open-ended questions was used to collect information on parental perceptions. To measure students' grit levels, the 8-Item Grit Scale, as developed by Duckworth and Quinn (2009) was used. In qualitative research, a questionnaire drawn from descriptive survey methodology provides generalizability about a sample that in-depth interviews cannot (De Vaus, 2002, p. 5). In addition, written questionnaires arguably provide a wealth of information given effective question design (Moser \& Kalton, 1972, p. 308). A self-administered approach allows for participants to select and input answers themselves which, on the one hand, opens the possibility of bias into the responses, but, on the other hand, eliminates potential for researcher bias when interpreting data (Fowler, 2009, p. 82).

There are two population groups that were sought for the study: parents and guardians of preadolescent students (both male and female, anticipated ages 30 years old and above), and preadolescent students in grades 4, 5, and 6 (ages 9 to 12 years old). As the main measurement was related to attitude and perception, the non-probability sample was based on availability, willingness to complete the survey, and the age of their child. The age of the adult respondents could vary, as the sample included primary caregivers of preadolescent children, rather than only biological parents.

Data collection commenced during the second week of the 2017-2018 school year. A total of 95 forms were sent home in September via classroom teachers across four classes at a Northern Ontario public school: Grade 3/4 (15 grade 4 students), Grade 4/5 (27 students), and two Grade $5 / 6$ classes (27 students and 26 students respectively). Using a non-probability availability sample, we aimed to receive at least 29 full questionnaire responses to maintain a $30 \%$ response rate $(30.5 \%)$. By the conclusion of the data collection period, one full questionnaire response had been submitted.

To address issues of nonresponse, the data collection process was repeated with the same sample in late November, with a two-week timeline to return Informed Consent Forms and completed hard copy questionnaires. Eight completed questionnaires were collected - an $8.4 \%$ response rate. This is a non-representative sample of the Junior student and parental/guardian population at the school. As such, the study data has been used only as a platform to begin shaping the landscape in considering parental and community perceptions in grit education. 


\section{Outcomes and Key Findings}

As predicted in its exploratory nature, this study touched on several aspects of current grit research, including current knowledge, current perceptions surrounding grit, and potential character education pedagogies.

Parents and guardians demonstrated some knowledge of grit regardless of whether or not they claimed to have prior knowledge about the trait. The data could be interpreted as understanding that "grit" is widely known and the general population may either have enough knowledge to discuss grit in educational terms, or may interpret or infer its definition. The notion has gained enough momentum to alert mainstream media and affect provincial educational practice. Whether or not parents and guardians are consciously aware of the term's definition in an educational setting is unclear; however the assumption can be made that a portion of the local population has been exposed to grit knowledge through the media. A second possibility for this correlation is the linking of language used in the questionnaire and in the Participant Information Letter. That is, key words used in defining grit as per Duckworth and her colleagues (2007), may have swayed the responses about what parents know about grit.

In completing the questionnaire (known as the Grit-S), children scored themselves higher on seven of eight questions than their parents and guardians scored them. In particular, children considered themselves to be harder workers by an average score of 0.75 higher than their parental counterparts. The correlation between the average scores of both parties could be analyzed to investigate whether or not this was the result of higher levels of parental involvement - suggesting that parental involvement adds to the confidence and feelings of support that children perceive (see Barwegen, Falciani, Putnam, Reamer, \& Stair, 2004). According to Conti (2001), self-esteem ultimately affects motivation and achievement, and self-esteem is directly linked to parental involvement and how parents view failure (p. 67). Alternatively, differing perceptions of language and clarity of concepts further justify the results of this study. How one student comprehends the qualities that embody "hard-working" may differ from how another student may perceive it, and these may differ from how their parents and guardians view the concept. This rings true for many of the concepts used in the Grit-S, such as "long-term," "obsessed," and even what a "goal" entails. Without being defined in the questionnaire itself, these concepts allow for interpretation and bias among respondents.

Two main themes that emerged among the open-ended question responses coincided with the idea of the growth mindset - that grit can be developed. These responses were coded into whether they demonstrated a perception of how schools should be, or whether they reference specific strategies for fostering grit.

Three of seven participants shared how they believed or hoped schools were for their child. However, a variance among the responses may signal a range of explanations, including confirmation bias and the general data collection strategies as a result of open expression of participants' lived experiences (Sutton \& Austin, 2015). In sharing perceptions of how schools should be, three views of education are recognized: those that centre on academic achievement, those that centre on motivation, and those that centre on instant and delayed gratification. 
When asked if and how their child's school community fostered grit, participants shared specific strategies they perceived currently in use to support their child's grit development, or that they perceived would support grit development. When analyzed alongside other current studies - both on grit and overlapping constructs - the strategies participants share mirror the strategies currently perceived to be in support of related grit constructs. These include goal-setting and positive teacher-student relationships.

Because of the small sample size, there were no significant patterns or relationships across the data as a whole. However, also as predicted, the study poses more questions and considerations for future research than providing resolutions. In particular, the results of the study provide some direction toward further perception research, research on parental involvement, and further assessments on grit measurement, and grit itself.

\section{Discussion}

\section{Perception Research}

In looking forward, considering the non-probability availability sampling points to the need for further perception research. The population-preadolescent students and their parents/guardians attending a public school in a Northern Ontario city - is not indicative of how results may vary if sampled across several populations across any jurisdiction. This limitation points to the need for further study to sample across several school boards to consider the impact of demographics and culture. When analyzing perceptions, $\mathrm{Ni}, \mathrm{Li}$, and Wang (2016) argued that the factors affecting perceptions of various participant groups depend largely on societal influence. Their view was similar to the possible explanation for differing scores among parents and students in this study's questionnaire: that is, "whether a child is resilient or not is determined in his or her context and culture" (Ni et al., 2016, p. 437).

Further research should also consider the sample population. This study focused on the correlations between students and their parents and guardians. The relationship between students and their teachers may yield vastly different responses, and may provide more insight if it is then correlated with the results provided by parents and guardians. Understanding the gaps and relationships between perceptions of different groups can provide a more accurate picture of the grit landscape, and can inform and improve interventions and programming (Ramsey, Spira, Parisi, \& Rebok, 2016, p. 631).

\section{Parental Involvement}

Parental involvement is a well-researched protective factor in promoting resilience and supporting a growth mindset in children (Bashant, 2014; Blackwell, Trzesniewski, \& Dweck, 2007; Jackson, Whitehead, \& Wigford, 2010). This study revealed that children may perceive themselves to be grittier than their parents and guardians perceive them to be. However, available research on how supportive familial relationships affect how children perceive themselves is limited.

Further study on parental involvement and grit may also influence programming in a direct way, especially if results correspond with current research on involvement. Meier and Lemmer 
(2015) believed "education should be a shared activity," recognizing that "schools and families [are] partners in the education of their children" (p. 1). Deslandes and Bertrand (2005) asserted that parental involvement plays a strong supporting role in education; however, involvement is more likely when participation is viewed as a requirement of schooling, rather than a voluntary activity (p. 165). Continual research on family influence and parental involvement discourages a grit ideology where all students must be gritty in order to achieve success (Gorski, 2016), and a property-first approach that prioritizes the construct of grit itself over individual growth (Peterson, 2015). Both the grit ideology and a property-first approach to fostering grit dismiss the protective and risk factors that affect the development of non-cognitive skills, including grit. Involving all parties in the development of a character education program supports the avoidance of both a grit ideology and a property-first approach through education on what it means to develop grit.

\section{Assessing Grit}

In promoting a measurement-first approach to assessing grit development, research in support of developing effective ways to measure grit would also influence school programming. This involves the promotion of individual, continual growth, rather than focusing on whether students are gritty or not. The Grit Scale and the Short Grit Scale (the Grit-S) provide researchers with measurement tools that remain consistent across grit research. However, the scale's predictive value is negatively affected by its lack of relation to grit's factor structure, its failure to address different age groups, and its inclination toward a property-first approach to fostering grit in students (Egalite, Mills, \& Greene, 2016; Muenks, Wigfield, Yang, \& O'Neal, 2017). While addressing the gaps in perception research and current findings on parental involvement, acknowledging the shortcomings of the current Grit-S and working towards more reliable measurement tools may provide the accountability that character education programming currently lacks (West et al., 2016). In fact, the search for reliable measurement tools should be a priority for educators who may be eager to "accelerate its [grit's] development" (Duckworth \& Gross, 2014, p. 202) in order to implement effective interventions.

\section{Re-evaluating the Significance of Grit}

Lastly, in assessing the results of this study, we begin questioning the very significance of grit within the current education landscape. Due to the long-term timelines Duckworth et al. (2007) presented in their definition of grit, Wolters and Hussain (2015) believed it was "impractical" for educators to focus on grit development (p. 307). Ni et al. (2016) were cautious, believing a reliance on resilience research may be more beneficial for prevention and intervention practices (p. 438). Other researchers (Golden, 2017; Saltman, 2014) argued for the focus to be shifted towards socio-economic issues, rather than adopting a grit ideology where educators promote grit as an all-encompassing solution to academic shortcomings. Finally, there remains a lack of research on how grit relates to other non-cognitive variables in predicting academic achievement. This is a stated limitation in the research of Duckworth and colleagues' (2007) inaugural studies on grit, and continues to ring true for other researchers. In examining the achievement of African American high school students, Dixson, Roberson, and Worrell (2017) 
found that "grit, growth mindset, ethnic identity, and other group orientation[s] all had trivial correlations with academic achievement" (p. 133). Muenks et al. (2017) also found no relationship between grit and later academic outcomes (p. 602). The correlation between grit and academic achievement remains inconsistently understood.

\section{Significance of the Research}

This study aimed to provide insight on preparing teachers to meet the needs of diverse populations through the fostering of grit in students. The incorporation of grit into public education spheres through character education initiatives indicate that the fostering of grit in schools should be taken seriously. However, the scope of research on pedagogies is limited and vague, including what educators and communities know about what grit is, and what it means to be gritty. Without this theoretical and pedagogical knowledge, educators are missing the first step towards confidently putting into place practices that will, in turn, affect their students. As a result, "teachers at a variety of levels ... have their doubts about the overall effectiveness of character education" (Waters \& Russell, 2017, p. 53). This aligns with the findings of Rizzo and Bajovic (2016) from their study on moral literacy among pre-service teachers: in order to fully implement character education, teacher preparation programs must provide pre-service teachers with theoretical knowledge on moral development (p. 131). The results of this study propose areas for further inquiry, including research on school stakeholder perceptions, parental involvement and grit, assessing and measuring grit, and the correlation between grit and academic achievement.

While the current study revealed some trends that correlate with research on other non-cognitive traits, such as resilience, the study revealed inconsistencies in what is known about fostering and assessing grit itself, which perhaps points to the premature incorporation of grit into character education programming. In turn, this affects the very roots of where teachers begin their journey into classrooms - their preservice training and if this entails theoretical and pedagogical training on character education. At the very least, grit researchers remain at the beginning of an expansive research journey. Going forward, we recommend these results be considered as next steps to be taken in order to develop meaningful, effective school programming.

\section{References}

Baldry, A. C. \& Farrington, D. P. (2005). Protective factors as moderators of risk factors in adolescence bullying. Social Psychology of Education, 8(3), 263-284. https://doi.org/10.1007/s11218-005-5866-5

Barwegen, L. M., Falciani, N. K., Putnam, S. J., Reamer, M. B., \& Stair, E. E. (2004). Academic achievement of homeschool and public school students and student perception of parent involvement. School Community Journal, 14(1), 39-58.

Bashant, J. (2014). Developing grit in our students: Why grit is such a desirable trait, and practical strategies for teachers and schools. Journal for Leadership and Instruction, 13(2), 14-17. 
Blackwell, L. S., Trzesniewski, K. H., \& Dweck, C. S. (2007). Implicit theories of intelligence predict achievement across and adolescent transition: A longitudinal study and an intervention. Child Development, 78(1), 246-263. https://doi.org/10.1111/j.1467-8624.2007.00995.x

Conti, M. (2001). How parents explain failure. (Doctoral dissertation). Retrieved from ERIC, ED455968.

De Vaus, D. (2002). Surveys in social research (5th Ed.). Australia: Allen \& Unwin. https://doi.org/10.4135/9781446263495

Deslandes, R. \& Bertrand, R. (2005). Motivation of parent involvement in secondary-level schooling. The Journal of Educational Research, 98(3), 164-175. https://doi.org/10.3200/JOER.98.3.164-175

Dixson, D. D., Roberson, C. C., \& Worrell, F. C. (2017). Psychosocial keys to African American achievement? Examining the relationship between achievement and psychosocial variables in high achieving African Americans. Journal of Advanced Academics, 28(2), 120-140. https://doi.org/10.1177/1932202X17701734

Duckworth, A. L. (2013, April). Angela Lee Duckworth: Grit: The power of passion and perseverance [Video file]. Retrieved from https://www.ted.com/talks/angela_lee_duckworth_grit_the_power_of_passion_and_persevera nce?language $=$ en

Duckworth, A. L. \& Gross, J. J. (2014). Self-control and grit: Related but separable determinants of success. Current Directions in Psychological Science, 23(5), 319-325. https://doi.org/10.1177/0963721414541462

Duckworth, A. L., Peterson, C., Matthews, M. D., \& Kelly, D. R. (2007). Grit: Perseverance and passion for long-term goals. Journal of Personality and Social Psychology, 92(6), 1087-1107. https://doi.org/10.1037/0022-3514.92.6.1087

Duckworth, A. L. \& Quinn, P. D. (2009). Development and validation of the Short Grit Scale (Grit-S). Journal of Personality Assessment, 91(2), 166-174. https://doi.org/10.1080/00223890802634290

Duckworth, A. L. \& Seligman, M. E. (2005). Self-discipline outdoes IQ in predicting academic performance of adolescents. Psychological Science, 16(12), 939-944. https://doi.org/10.1111/j.1467-9280.2005.01641.x

Duckworth, A. L. \& Seligman, M. E. (2006). Self-discipline gives girls the edge: Gender in self-discipline, grades, and achievement test scores. Journal of Educational Psychology, 98(1), 198-208. https://doi.org/10.1037/0022-0663.98.1.198

Duckworth, A. L. \& Yaeger, D. S. (2015). Measurement matters: Assessing personal qualities other than cognitive ability for educational purposes. Educational Researcher, 44(4), 237-251. https://doi.org/10.3102/0013189X15584327 
Egalite, A. J., Mills, J. N., \& Greene, J. P. (2016). The softer side of learning: Measuring students' non-cognitive skills. Improving Schools, 19(1), 27-40. https://doi.org/10.1177/1365480215616313

Eisman, A. B., Stoddard, S. A., Heinze, J., Caldwell, C. H., \& Zimmerman, M. A. (2015). Depressive symptoms, social support, and violence exposure among urban youth: A longitudinal study of resilience. Developmental Psychology, 51(9), 1307-1316. https://doi.org/10.1037/a0039501

Fowler, F. J. (2009). Survey research methods (4th Ed.). Thousand Oaks, CA: Sage. https://doi.org/10.4135/9781452230184

Golden, N. A. (2017). “There's still that window that's open”: The problem with "Grit". Urban Education, 52(3), 343-369. https://doi.org/10.1177/0042085915613557

Gorski, P. C. (2016). Poverty and the ideological imperative: A call to unhook from deficit and grit ideology and to strive for structural ideology in teacher education. Journal of Education for Teaching, 42(4), 378-386. https://doi.org/10.1080/02607476.2016.1215546

Hutton, P. (2015, September 21). Fostering grit in today's students, classrooms and schools. Huffington Post. Retrieved from https://www.huffingtonpost.com/peter-hutton/fostering-grit-in-todays-_b_8170194.html

Jackson, E., Whitehead, J., \& Wigford, A. (2010). In an EBD population do Looked After Children have specific needs relating to resilience, self-perception and attainment? $\begin{array}{lllll}\text { Educational Psychology in } & \text { 69-77. }\end{array}$ https://doi.org/10.1080/02667360903522793

Karkkainen, R., Raty, H., \& Kasanen, K. (2009). Parents' perceptions of their child's resilience and competencies. European Journal of Psychology of Education, 24(3), 405-419. https://doi.org/10.1007/BF03174769

Knupfer, N. N. \& McLellan, H. (2001) Descriptive research methodologies. In D. H. Jonassen (Ed.), Handbook of research for educational communications and technology (1196-1212). New York, NY: Simon \& Schuster Macmillan.

Meier, C. \& Lemmer, E. (2015). What do parents really want? Parents' perceptions of their children's schooling. South African Journal of Education, 35(2), 1-11. https://doi.org/10.15700/saje.v35n2a1073

Moser, C. A. \& Kalton, G. (1972) Survey methods in social investigation (2nd ed.). New York, NY: Basic Books.

Muenks, K., Wigfield, A., Yang, J. S., \& O’Neal, C. R. (2017). How true is grit? Assessing its relations to high school and college students' personality characteristics, self-regulation, engagement, and achievement. Journal of Educational Psychology, 109(5), 599-620. https://doi.org/10.1037/edu0000153 
Ni, H., Li, C., \& Wang, C. (2016). Students' perceptions of resilience promoting factors in Chinese and American middle schools. School Psychology International, 37(5), 435-455. https://doi.org/10.1177/0143034316664391

Ontario Ministry of Education. (2008). Finding common ground: Character development in Ontario schools, K-12. Retrieved from https://www.edu.gov.on.ca/eng/document/reports/literacy/booklet2008.pdf

Ontario Ministry of Education (2016). About innovation in learning in Ontario. Retrieved from http://www.edugains.ca/newsite/21stCenturyLearning/about_learning_in_ontario.html

Ontario Ministry of Education (2018). 21st century competencies: Foundation document for discussion.

Retrieved

from

http://www.edugains.ca/resources21CL/21stCenturyLearning/21CL_21stCenturyCompetenci es.pdf

Perlis, M. M. (2013, October 29). 5 characteristics of grit: How many do you have? Forbes. Retrieved

from https://www.forbes.com/sites/margaretperlis/2013/10/29/5-characteristics-of-grit-what-it-is-w hy-you-need-it-and-do-you-have-it/\#232c12394f7b

Peterson, D. (2015). Putting measurement first: Understanding 'grit' in educational policy and practice. Journal of Philosophy of Education, 49(4), 571-589. https://doi.org/10.1111/1467-9752.12128

Ramsey, C. M., Spira, A. P., Parisi, J. M., \& Rebok, G. W. (2016). School climate: perceptual differences between students, parents, and school staff. School Effectiveness and School Improvement, 27(4), 629-641. https://doi.org/10.1080/09243453.2016.1199436

Rizzo, K. \& Bajovic, M. (2016). Moral literacy through two lenses: Pre-service teachers' preparation for character education. International Journal of Teaching and Learning in Higher Education, 28(1), 131-138.

Saltman, K. (2014). The austerity school: Grit, character, and the privatization of public education. Symploke, 22(1), 41-57. https://doi.org/10.5250/symploke.22.1-2.0041

Sutton, J. \& Austin, Z. (2015). Qualitative research: Data collection, analysis, and management. The Canadian Journal of Hospital Pharmacy, 68(3), 226-231. https://doi.org/10.4212/cjhp.v68i3.1456

Von Culin, K.R ., Tsukayama, E., \& Duckworth, A. L. (2014). Unpacking grit: Motivational correlates of perseverance and passion for long-term goals. The Journal of Positive Psychology, 9(4), 306-312. https://doi.org/10.1080/17439760.2014.898320

Waters, S. \& Russell, W. B. (2017). Preservice secondary teachers' sense of efficacy in teaching character education. Journal of Education, 194(2), 45-54. https://doi.org/10.1177/002205741419400206 


\section{Macrothink}

Journal of Studies in Education

ISSN 2162-6952 2019, Vol. 9, No. 2

Wente, M. (2016, February 20). Why grit is highly overrated. The Globe and Mail. Retrieved from

https://www.theglobeandmail.com/opinion/why-grit-is-highly-overrated/article28815854/

West, M. R., Kraft, M. A., Finn, A. S., Martin, R. E., Duckworth, A. L., Gabrieli, C. F., Gabrieli, J. D. (2016). Promise and paradox: Measuring students' non-cognitive skills and the impact of schooling. Educational Evaluation and Policy Analysis, 38(1), 148-170. https://doi.org/10.3102/0162373715597298

Wolters, C. A. \& Hussain, M. (2015). Investigating grit and its relations with college students' self-regulated learning and academic achievement. Metacognition Learning, 10(3), 293-311. https://doi.org/10.1007/s11409-014-9128-9 